\title{
First comprehensive tool for screening pain in Parkinson's disease: The King's Parkinson's Disease Pain Questionnaire (KPPQ)
}

Pablo Martinez-Martin ${ }^{1,2 \dagger}$, Alexandra M. Rizos ${ }^{3 \dagger}$, John Wetmore ${ }^{1}$, Angelo Antonini ${ }^{4}$, Per Odin ${ }^{5}$, Suvankar $\mathrm{Pal}^{6}$, Rani Sophia ${ }^{7}$, Camille Carroll ${ }^{8}$, Davide Martino ${ }^{9}$, Cristian Falup-Pecurariu ${ }^{10}$, Belinda Kessel ${ }^{11}$, Thomasin Andrews ${ }^{12}$, Dominic Paviour ${ }^{13}$, Claudia Trenkwalder ${ }^{14}$, Kallol Ray Chaudhuri, DSc ${ }^{3}$ on behalf of EUROPAR \& MDS Non-Motor PD Study Group

${ }^{1}$ National Center of Epidemiology, Carlos III Institute of Health, Madrid, Spain;

${ }^{2}$ Center for Networked Biomedical Research in Neurodegenerative Diseases (CIBERNED), Carlos III Institute of Health, Madrid, Spain;

${ }^{3}$ Institute of Psychiatry, Psychology \& Neuroscience at King's College and King's College Hospital NHS Foundation Trust

${ }^{4}$ Neurology, University of Padua, Venice, Italy.

${ }^{5}$ Neurology, University of Lund, Lund, Sweden

${ }^{6}$ Neurology, Forth Valley Royal Hospital, Larbert, Scotland, UK;

${ }^{7}$ Geriatric Medicine, Yeovil Hospital, Somerset, UK;

${ }^{8}$ Neurology, Derriford Hospital, Plymouth, UK;

${ }^{9}$ Department of Clinical Neurosciences, University of Calgary, Calgary, Canada;

${ }^{10}$ Neurology, Transylvania University, Brasov, Romania;

${ }^{11}$ Medicine for the Elderly, Princess Royal University Hospital site, King's College Hospital, Kent, UK;

${ }^{12}$ Neurology, Guy's Hospital, London, UK;

${ }^{13}$ Neurology, St Georges's Hospital, London, UK;

${ }^{14}$ Department of Neurosurgery, University Medical Center, Goettingen, Germany

† These authors contributed equally to the manuscript 


\section{Correspondence to}

P. Martinez-Martin, MD, PhD

National Center of Epidemiology

Carlos III Institute of Health

Avenida Monforte de Lemos, 5

28029 - Madrid

Spain

Phone: +34 918222618

Fax: +34 913877815

E-mail:pmartinez@isciii.es

Running title: The King's Parkinson's Disease Pain Questionnaire

Conflict of interest: The authors declare no conflict of interest for this manuscript, except Dr. K. Ray Chaudhuri, C. Trenkwalder, and P. Martinez-Martin who have a license copyright on the King's Parkinson's Disease Pain Scale.

Word Count: Total word + Table legends $=3999$ 


\section{Abstract}

Background: Pain is highly prevalent in Parkinson's disease (PD), impacting patients' ability, mood, and quality of life. Detecting the presence of pain in its multiple modalities is necessary for adequate personalized management of PD. A 14-item, PD-specific, patient-based questionnaire (the King's Parkinson's disease Pain Questionnaire, KPPQ) was designed corresponding to the rater-based KPP Scale (KPPS). The present multi-center study was aimed at testing the validity of this screening tool. Methods: First, a comparison between the KPPQ scores of patients and matched controls was performed. Next, convergent validity, reproducibility (test-retest), and diagnostic performance of the questionnaire were analyzed.

Results: We report data from 300 patients and 150 controls. PD patients declared significantly more pain symptoms than controls $(3.96 \pm 2.56$ vs. $2.17 \pm 1.39 ; p<0.0001)$. KPPQ convergent validity with KPPS total score was high $\left(r_{s}=0.80\right)$, but weak or moderate with other pain assessments. Test-retest reliability was satisfactory with kappa values $\geq 0.65$, except for item 5 , Dyskinetic pains (kappa=0.44) and ICC for the KPPQ total score 0.98 .

After the scores of the KPPS were adapted for screening ( $0=$ no symptom; $\geq 1=$ symptom present), a high agreement was found between the KPPQ and the KPPS (ICC $=0.88)$. A strong correlation $\left(r_{S}=0.80\right)$ between both instruments was found. The diagnostic parameters of the KPPQ were very satisfactory as a whole, with a global accuracy of $78.3 \%-98.3 \%$.

Conclusions: These results suggest that the KPPQ is a useful, reliable, and valid screening instrument of pain in PD to advance patient-related outcomes.

Key words: Parkinson's disease; Pain; Assessment; Screening; King's Parkinson's disease Pain Questionnaire; KPPQ; Validation 


\section{Introduction}

The prevalence of pain in PD has been estimated to be around 68\% (range: $40 \%-85 \%$ ) [1]. However, pain in PD is still underdiagnosed and often undeclared [2], and only about half (52.4\%) of PD patients with pain use analgesics [1].

Furthermore, PD patients with pain are more likely to suffer from anxiety, depression, and worsened sleep quality [3]. Pain has also been shown to interfere with work and other activities of daily living to some extent in these PD patients [4,5]. Because of the multidimensional effect of pain in PD, it is one of the most relevant determinant factors of healthrelated quality of life in general [6] and in PD $[7,8]$.

Several types of pain may be present in PD (e.g. dystonic, musculoskeletal, central, and radicular) [9] and accumulate in a single patient, complicating the management of this nonmotor symptom [10]. Moreover, the pathophysiology of pain in PD is complex, with peripheral(rigidity, dystonia), spinal cord- (intermediolateral cell column), and brain-related (deficiency of monoamines in the brain stem) origins [11,12].

Due to their inherent difficulty for assessment, the rater-based King's Parkinson's disease Pain Scale (KPPS) was developed to evaluate the multiple pain modalities present in PD patients [13]. However, the KPPS is administered by healthcare professionals; therefore, a need for a valid patient-completed questionnaire exists. For this reason, the King's College Parkinson's Disease Pain Questionnaire (KPPQ) was created with the support of CRISP (Community for Involvement and Support for people with Parkinson's), an expert patient group based at King's College Hospital, to ensure comprehensibility for laypersons by using appropriate wording and logically ordering the questions.

The KPPQ (Appendix 1), a time-efficient and easy-to-understand 14-item screening questionnaire is composed solely of "Yes" or "No" questions that assess whether or not a 
specific type of pain is present, similarly to the widely-used Non-Motor Symptoms Questionnaire [14]. Since the patient-completed KPPQ is a derivative of the rater-completed KPPS, each question of the KPPQ corresponds to one of the items of the KPPS. Even though the KPPQ does not use domains to group these 14 items, both the KPPS and the KPPQ address the same specific types of pain.

The objective of this multicenter study is to determine the validity and reliability of the KPPQ using a sample of PD patients and healthy controls.

\section{Methods}

$\underline{\text { Design }}$

International, multi-center, observational, cross-sectional study.

\section{Patients}

Consecutive PD patients with a diagnosis of PD (according to the UK PD Brain Bank criteria) [15] who answered "Yes" to question 10 of the Non-Motor Symptoms Questionnaire, "Unexplained pains (not due to known conditions)," [14] were included in this study. Exclusion criteria were: (1) Patients with alternative or uncertain diagnosis of Parkinson's and druginduced Parkinson's; (2) inability to give consent; (3) presence of dementia formally diagnosed following internationally-accepted criteria; and (4) diagnosis of identifiable conditions causing pain unrelated to PD (e.g. severe osteoarthritis, known malignancy, rheumatoid arthritis, polymyalgia rheumatica, fibromyalgia, etc.).

For this study, a sample size of 300 patients was proposed considering both the potential variability and confounding effect of a patient-completed assessment and the number of participating sites.

Patients were recruited from August 2013 to February 2016 from movement disorder units of nine different centers across the UK as well as Romania. In the UK, the study was adopted to the National Institute of Health Research portfolio of studies (UKCRN No. 13344). 


\section{Controls}

A sample of 150 controls (ratio of patients:controls $=2: 1$ ) matched by age and sex was assessed by means of the KPPQ. Exclusion criteria overlapped exclusion criteria 2 through 4 for patients.

\section{Assessments}

For both patients and controls, information regarding socio-demographic and PD historical data were recorded.

In addition to the KPPQ, the following instruments for PD were applied (see Supplementary material for details): KPPS [13], Hoehn and Yahr classification (HY) [16], Scales for Outcomes in Parkinson's Disease-Motor (SCOPA-Motor) [17], Non-Motor Symptoms Scale (NMSS) [18], Clinical Impression of Severity Index for PD (CISI-PD) [19], Visual Analog Scales (VAS) for pain severity and frequency [20], Hospital Anxiety and Depression Scale (HADS) [21], EQ-5D [22], PD Quality of Life Questionnaire (PDQ-8) [23], and Parkinson's Disease Sleep Scale-Version 2 (PDSS-2) [24].

Levodopa Equivalent Dose (LEDD) was calculated according to Tomlinson et al. 2010 [25].

In the control group, the following assessments were collected: KPPQ, HADS, and EQ-5D.

\section{Procedures}

Patients were assessed in the optimally "on" state. Test-retest reliability of the KPPQ was evaluated by means of a second application of the questionnaire in patients who remained stable with respect to pain as per the pain VAS.

\section{Ethical Issues}

This study was approved by the hospital ethical committees/institutional review boards of the participant centers. All participants provided informed consent prior to joining the study.

\section{Data Analysis}


For each participant, a KPPQ "total score" (KPPQ-TS) was calculated by summing the number of "Yes" responses. Also, to compare the performance of the KPPQ with the KPPS that was taken as "gold standard," the KPPQ items were grouped in domains according to those of the scale. For both the NMSQ and NMSS, the prevalence of the diverse types of pain was determined by the proportion of individuals responding positively each item (score $\geq 1$ ), considering a score of 0 as the absence of the symptom.

Distribution of data was not normal (Shapiro-Francia test); therefore, non-parametric statistics were used. The differences between patients and controls were analyzed using the chi-square, Mann-Whitney $U$, and McNemar chi-square tests. Association between measures was determined by the Spearman rank correlation coefficient. A high correlation $\left(r_{s}>0.70\right)$ of the KPPQ-TS with KPPS total score was hypothesized, whereas moderate or weak correlations $\left(r_{S}=\right.$ $\leq 0.70)[26]$ were expected with other variables.

For concordance between the prevalence detected by corresponding items of KPPQ and KPPS, and for test-retest reliability, Cohen's kappa index for items, and ICC for total scores were determined.

Finally, sensitivity, specificity, positive and negative predictive values, and accuracy of the KPPQ were calculated against the corresponding components of the KPPS.

For more detail, see the Supplementary material.

\section{Results}

We report data from 300 patients and 150 controls matched by age and gender. There were no significant differences between patients and controls in reference to age (mean \pm SD:

$64.86 \pm 10.54$ vs. $64.86 \pm 10.23 ; p=0.90)$, sex (males, $59.7 \%$ vs. $60 \% ; p=0.95)$, ethnics $(p=0.63)$, and education years ( $14.11 \pm 3.99$ vs. $14.39 \pm 3.93 ; p=0.33$ ). Median (and interquartile range) HY of patients was $2(2-3$; limits: $1-5)$.

HADS and EQ-5D assessments showed significantly higher levels of depression (6.62 \pm 4.39 ), anxiety (5.45 \pm 3.82$)$, and worse quality of life $(0.57 \pm 0.27)$ in PD patients when compared to the levels of depression $(5.09 \pm 3.57)$, anxiety $(3.90 \pm 3.01)$, and overall quality of life $(0.78 \pm 0.22)$ in 
controls $(p<0.0001$ to $p=0.0006)$. Significant differences were also found in the proportion of subjects with positive responses on the KPPQ for $50 \%$ of the items and three out of the seven domains after Bonferroni correction (Table 1). When comparing KPPQ-TS, patients declared more pain symptoms than controls $(3.96 \pm 2.56$ vs. $2.17 \pm 1.39 ; p<0.0001)$.

In patients, the proportion of positive responses to the KPPQ was compared with those of the KPPS, and a significant difference was found in only one item (6. Painful cramps during off periods) of the KPPQ and one domain (3. Fluctuation-related pain) (Table 1).

The agreement between KPPQ and KPPS prevalence showed kappa values from 0.56 (KPPQ items 6 and 7) to 0.86 (item 14), with 11 items (78.6\%) reaching kappa values greater than 0.60 (substantial agreement). Overall, the KPPQ-TS and KPPS "total score of prevalence" displayed a high level of concordance $($ ICC $=0.88)$.

Table 2 shows the correlations of the KPPQ-TS with other pain measures. While a tight correlation with the KPPS total score $\left(r_{S}=0.80\right)$ was found, coefficients were weak/moderate with the other pain measures $\left(r_{S}=0.31-0.46\right)$. The KPPS total score, however, showed mildly higher correlation coefficient values with these pain assessments $\left(r_{s}=0.47-0.50\right)$.

To test the reproducibility of the KPPQ, a second application was carried out in 52 patients at a mean interval of $11.8 \pm 4.4$ days (range: $7-28$ ). No significant differences between applications were found for the VAS-TS (Wilcoxon signed-rank test; $p=0.52)$ and the KPPQ-TS $(p=0.76)$. Kappa values were $\geq 0.65$ for all KPPQ items, with exception of one item (5. Dyskinetic pains; kappa=0.44) (Table 3). ICC for the KPPQ-TS was 0.98.

The results of KPPQ diagnostic parameters were satisfactory, with values running from $61.4 \%$ to $99.3 \%$ (Table 4 ). The global accuracy of the KPPQ components ranged from $78.3 \%$ to $98.3 \%$

\section{Discussion}

This is the first report of a validation of a patient-completed pain questionnaire specifically developed for PD. This patient-completed screening tool was derived from the KPPS and allows for the direct declaration of the pain each patient experiences.

Prevalent in the prodromal, early, advanced, and palliative stages of PD, pain is one of its most important non-motor symptoms [27-29] and was described by James Parkinson himself in his case number $4[30,31]$. Neuropathological correlates of pain in early and untreated PD have 
been described, [32] and pain is also featured as one of the most prevalent and troublesome symptoms in the late palliative stage of PD $[28,33]$.

Despite the importance and high frequency of pain in PD [34], studies suggest that pain is under-reported and often not considered in clinical consultations [2]. In part, this is related to the lack of a validated self-declared tool specifically developed considering the diversity of pain in PD. KPPQ was developed considering this conceptual framework and to empower patients to declare pain.

Our analysis showed that, when the KPPQ was applied in patients and matched controls, the prevalence of the different varieties of pain was significantly greater in PD patients in half of the pain modalities and in three out of the seven domains. These results are expected because pain is experienced by both the elderly and PD patients. However, when considering the differences between KPPQ-TS, patients declared significantly more symptoms than controls.

Consistent with previous findings, patients with pain displayed higher rates of depression and anxiety [3]. Some estimates show that chronic pain can increase the risk for depression, yet a link in the opposite direction is unclear $[35,36,37]$. It is hypothesized that the link between pain and depression could be due to neuroinflammation [36]. In PD, pain-related disability also correlates with depression and anxiety [38].

Prior research has shown that pain is a determinant of quality of life in all populations [39] and that PD considerably deteriorates patients' HRQoL [40,41]. The non-motor symptom burden of PD, which includes pain, can affect HRQoL with a greater impact than the motor symptoms [4245].

The convergent validity of the KPPQ was assessed using other pain measures. While weak and moderate correlations were found between these measures and the KPPQ, the KPPS showed higher levels of correlations with these scales. However, it is important to note that the KPPQ is only a screening tool, whereas the KPPS is a quantitative measure of pain severity and frequency in PD and is more closely related to the scales with which both were compared. Nevertheless, the KPPQ showed moderate correlations with PD-related variables (i.e. SCOPA Motor, NMSS, CISI-PD, PDSS-2, and PDQ-8) as well as other measures (i.e. HADS - Anxiety, HADS - Depression, and EQ-5D). The weak correlation between the KPPQ and LEDD and between the KPPQ and $\mathrm{HY}$ staging suggest that there is no relation between PD progression and the number of pain symptoms experienced by the patient despite previous findings suggesting a relationship between pain and motor impairment severity [4]. 
Concerning the reproducibility of the KPPQ, there was significant agreement in each item between both applications of the KPPQ, except for one (5. Dyskinetic pains), and for the KPPQ-TS. These findings lead to the conclusion that the KPPQ is an instrument with satisfactory reproducibility.

When comparing the KPPQ to the KPPS, there were significant differences in the proportion of positive responses for only one item and one domain. This can be explained by the differences in the wording of the corresponding item in the KPPQ (6. Painful cramps in a region during "off" periods) and in the KPPS (5. Pain in a region during "Off" dystonia). Otherwise, there was significant agreement between KPPQ and KPPS prevalence for each item, suggesting that they are equivalent when the KPPS is used as a screening tool. There were also a high level of concordance and a strong correlation between the total scores for both instruments.

Finally, the satisfactory capabilities of the KPPQ for screening are clear based on its high sensitivity, specificity, and predictive values. Overall, the KPPQ was shown to detect with a high accuracy the presence of the diverse pain modalities in PD. Yet, a limitation of our study is the assumption that a variety of comorbidities may not cause significantly increased pain and may be evenly-distributed among patients and controls. Therefore, we did not control for comorbidities that may not necessarily cause pain, such as diabetes.

However, from these results, it is inferred that the KPPQ is a useful, valid, and reliable, patient-completed instrument to assess pain in PD. We propose that KPPQ be provided to every patient who answers "yes" to the relevant pain related question in the Non-Motor Symptoms Questionnaire, which is now globally applied and regarded as a quality standard for the clinical assessment of PD. As both are patient-completed tools, they can be completed while waiting to be seen, optimizing consultation time. Utilization of this strategy in clinics would ensure that pain is not under-reported or under-recognized in clinical practice. 


\section{Acknowledgments}

This paper represents independent research part funded by the NIHR Biomedical Research

Centre South London/Maudsley NHS Foundation Trust/King's College London. The views expressed are those of the author(s). 


\section{References}

1. Broen MP, Braaksma MM, Patijn J, Weber WE. Prevalence of pain in Parkinson's disease: a systematic review using the modified QUADAS tool. Mov Disord 2012; 27: 480-484.

2. Chaudhuri KR, Prieto-Jurcynska C, Naidu Y, et al. The nondeclaration of nonmotor symptoms of Parkinson's disease to health care professionals: an international study using the nonmotor symptoms questionnaire. Mov Disord 2010; 25: 704-709.

3. Rana AQ, Qureshi ARM, Kachhvi HB, Rana MA, Chou KL. Increased likelihood of anxiety and poor sleep quality in Parkinson's disease patients with pain. J Neurol Sci 2016; 369: 212-215.

4. Allen NE, Wong CM, Canning CG, Moloney N. The Association Between Parkinson's Disease Motor Impairments and Pain. Pain Med 2016; 17: 456-462.

5. Fu YT, Mao CJ, Ma LJ, et al. Pain Correlates with Sleep Disturbances in Parkinson's Disease Patients. Pain Pract 2017.

6. Martinez-Martin P. What is quality of life and how do we measure it? Relevance to Parkinson's disease and movement disorders. Mov Disord 2017; 32: 382-392.

7. Martinez-Martin $P$. The importance of non-motor disturbances to quality of life in Parkinson's disease. J Neurol Sci 2011; 310: 12-16.

8. Martinez-Martin P, Manuel Rojo-Abuin J, Rizos A, et al. Distribution and impact on quality of life of the pain modalities assessed by the King's Parkinson's disease pain scale. NPJ Parkinsons Dis 2017; 3: 8.

9. Rana AQ, Kabir A, Jesudasan M, Siddiqui I, Khondker S. Pain in Parkinson's disease: analysis and literature review. Clin Neurol Neurosurg 2013; 115: 2313-2317.

10. Valkovic $\mathrm{P}$, Minar M, Singliarova $\mathrm{H}$,et al. Pain in Parkinson's Disease: A cross-sectional study of its prevalence, types, and relationship to depression and quality of life. PLoS One 2015; 10: e0136541.

11. Thompson T, Gallop K, Correll CU, et al. Pain perception in Parkinson's disease: A systematic review and meta-analysis of experimental studies. Ageing Res Rev 2017; 35: 74-86.

12. Tseng MT, Lin CH. Pain in early-stage Parkinson's disease: Implications from clinical features to pathophysiology mechanisms. J Formos Med Assoc 2017; 116: 571-581.

13. Chaudhuri KR, Rizos A, Trenkwalder $C$, et al. King's Parkinson's disease pain scale, the first scale for pain in PD: An international validation. Mov Disord 2015; 30: 1623-1631.

14. Chaudhuri KR, Martinez-Martin $\mathrm{P}$, Schapira $\mathrm{AH}$, et al. International multicenter pilot study of the first comprehensive self-completed nonmotor symptoms questionnaire for Parkinson's disease: The NMSQuest study. Mov Disord 2006; 21: 916-923. 
15. Gibb WR, Lees AJ. The relevance of the Lewy body to the pathogenesis of idiopathic Parkinson's disease. J Neurol Neurosurg Psychiatry 1988; 51: 745-752.

16. Hoehn MM, Yahr MD. Parkinsonism: onset, progression, and mortality. Neurology 1967; 17: 427-442.

17. Marinus J, Visser M, Stiggelbout AM, et al. A short scale for the assessment of motor impairments and disabilities in Parkinson's disease: the SPES/SCOPA. J Neurol Neurosurg Psychiatry 2004; 75: 388-395.

18. Chaudhuri KR, Martinez-Martin P, Brown RG, et al. The metric properties of a novel nonmotor symptoms scale for Parkinson's disease: results from an international pilot study. Mov Disord 2007; 22: 1901-1911.

19. Martinez-Martin P, Forjaz MJ, Cubo E, Frades B, de Pedro Cuesta J, ELEP Project Members. Global versus factor-related impression of severity in Parkinson's disease: A new clinimetric index (CISI-PD). Mov Disord 2006; 21: 208-214.

20. Jensen MP, Karoly P. Self-report scales and procedures for assessing pain in adults. In: Turk DC, Melzack R, eds. Handbook of Pain Assessment. New York: Guilford Press, 2001: 1534.

21. Zigmond AS, Snaith RP. The hospital anxiety and depression scale. Acta Psychiatr Scand 1983; 67: 361-370.

22. EuroQol Group. EuroQol- a new facility for the measurement of health related quality of life. Health Policy 1990; 16: 199-208.

23. Jenkinson C, Fitzpatrick R, Peto V, Greenhall R, Hyman N. The PDQ-8: development and validation of a short-form Parkinson's disease questionnaire. Psychology \& Health 1997; 12: 805-814.

24. Trenkwalder C, Kohnen K, Högl B, et al. Parkinson Disease Sleep Scale - Validation of the Revised Version PDSS-2. Mov Disord 2011: 26: 644-652.

25. Tomlinson CL, Stowe R, Patel S, Rick C, Gray R, Clarke CE. Systematic review of levodopa dose equivalency reporting in Parkinson's disease. Mov Disord 2010; 25: 26492653.

26. Simon SD. Statistical evidence in medical trials. Oxford: Oxford Univ. Press, 2006: 147.

27. Zis P, Erro R, Walton CC, Sauerbier A, Chaudhuri KR. The range and nature of non-motor symptoms in drug-naive Parkinson's disease patients: a state-of-the-art systematic review. NPJ Parkinsons Dis 2015; 1: 15013.

28. Schapira AHV, Chaudhuri KR, Jenner P. Non-motor features of Parkinson disease. Nat Rev Neurosci 2017; 18: 435-450.

29. Titova N, Padmakumar C, Lewis SJG, Chaudhuri KR. Parkinson's: a syndrome rather than a disease? J Neural Transm (Vienna) 2017; 124: 907-914. 
30. Politis M, Wu K, Molloy S, G Bain P, Chaudhuri KR, Piccini P. Parkinson's disease symptoms: the patient's perspective. Mov Disord 2010; 25: 1646-1651.

31. Lin $\mathrm{CH}$, Wu RM, Chang HY, Chiang YT, Lin HH. Preceding pain symptoms and Parkinson's disease: a nationwide population-based cohort study. Eur J Neurol 2013; 20: 13981404.

32. Jellinger KA. Neuropathobiology of non-motor symptoms in Parkinson disease. $J$ Neural Transm (Vienna) 2015; 122: 1429-1440.

33. Hely MA, Reid WG, Adena MA, Halliday GM, Morris JG. The Sydney multicenter study of Parkinson's disease: the inevitability of dementia at 20 years. Mov Disord 2008; 23: 837-844.

34. Ford, B. Pain in Parkinson's disease. Mov. Disord 2010; 25(Suppl. 1): S98-S103.

35. Bair MJ, Robinson RL, Katon W, Kroenke K. Depression and pain comorbidity: a literature review. Arch Intern Med 2003; 163: 2433-2445.

36. Zis P, Daskalaki A, Bountouni I, Sykioti P, Varrassi G, Paladini A. Depression and chronic pain in the elderly: links and management challenges. Clin Interv Aging 2017; 12: 709-720.

37. Antonini A, Tinazzi M, Abbruzzese G, et al. Pain in Parkinson's disease: facts and uncertainties. Eur J Neurol 2018. DOI: 10.1111/ene.13624.

38. Rana AQ, Qureshi ARM, Rahman N, Mohammed A, Sarfraz Z, Rana R. Disability from pain directly correlated with depression in Parkinson's disease. Clin Neurol Neurosurg 2017; 160: 14.

39. Raggi A, Corso B, Minicuci N, et al. Determinants of Quality of Life in Ageing Populations: Results from a Cross-Sectional Study in Finland, Poland and Spain. PLoS One 2016; 11: e0159293.

40. Martínez-Martín P. An introduction to the concept of "quality of life in Parkinson's disease". $J$ Neurol 1998; 245(Suppl. 1): 2-5.

41. Schrag A, Jahanshahi M, Quinn N. How does Parkinson's disease affect quality of life? A comparison with quality of life in the general population. Mov Disord 2000; 15: 1112-1118.

42. Quittenbaum BH, Grahn B. Quality of life and pain in Parkinson's disease: a controlled cross-sectional study. Parkinsonism Relat Disord 2004; 10: 129-136.

43. Rahman S, Griffin HJ, Quinn NP, Jahanshahi M. Quality of life in Parkinson's disease: the relative importance of the symptoms. Mov Disord 2008; 23: 1428-1434.

44. Martinez-Martin P, Rodriguez-Blazquez C, Kurtis MM, Chaudhuri KR. The impact of nonmotor symptoms on health-related quality of life of patients with Parkinson's disease. Mov Disord 2011; 26: 399-406. 
45. Bugalho P, Lampreia T, Miguel R, Mendonça MD, Caetano A, Barbosa R. Non-Motor symptoms in Portuguese Parkinson's Disease patients: correlation and impact on Quality of Life and Activities of Daily Living. Scient Reports 2016; 6: 32267. 
Table 1 - Prevalence ${ }^{\dagger}$ of pain modalitites according to the King's Parkinson's Disease Pain Questionnaire

\begin{tabular}{|l|c|c|c|c|c|}
\hline \multirow{2}{*}{ Items } & \multicolumn{2}{|c|}{ KPP Questionnaire } & \multicolumn{2}{c|}{ KPP Scale } \\
\cline { 2 - 6 } & Controls & Patients & $\mathbf{p}^{*}$ & Patients & $\mathbf{p}^{\text {** }}$ \\
\hline 1. Pain around joints & 77.33 & 78.67 & 0.75 & 81.33 & 0.046 \\
\hline 2. Pain related to internal organ & 13.33 & 19.67 & 0.096 & 21.00 & 0.41 \\
\hline $\begin{array}{l}\text { 3. Generalised non-specific pain in your } \\
\text { stomach area }\end{array}$ & 11.33 & 19.00 & 0.039 & 17.67 & 0.43 \\
\hline 4. Pain deep within the body & 19.33 & 32.33 & 0.0004 & 31.67 & 0.77 \\
\hline 5. Dyskinetic pain & 0 & 16.67 & $<0.0001$ & 17.00 & 0.86 \\
\hline $\begin{array}{l}\text { 6. Painful cramps in a region during "off" } \\
\text { periods }\end{array}$ & 11.33 & 48.33 & $<0.0001$ & 32.67 & $<0.0001$ \\
\hline 7. Generalized "off" period pain & 0.67 & 24.67 & $<0.0001$ & 22.33 & 0.31 \\
\hline 8. PLM or RLS-associated pain & 14.67 & 32.67 & $<0.0001$ & 28.00 & 0.023 \\
\hline 9. Pain while turning in bed & 18.67 & 48.33 & $<0.0001$ & 47.67 & 0.69 \\
\hline 10. Pain when chewing & 4.67 & 6.67 & 0.40 & 6.67 & 1.0 \\
\hline 11. Pain due to grinding teeth & 6.00 & 6.00 & 1.00 & 5.67 & 0.74 \\
\hline 12. Burning sensation in the mouth & 5.33 & 3.00 & 0.22 & 2.67 & 0.65 \\
\hline 13. Burning pain in the limbs & 12.00 & 18.00 & 0.10 & 18.33 & 0.87 \\
\hline 14. Shooting pain/pins \& needles & 22.00 & 42.33 & $<0.0001$ & 41.67 & 0.65 \\
\hline Domains & Controls & Patients & $\mathbf{p}^{*}$ & Patients & p \\
\hline 1. Musculoskeletal pain & 77.33 & 78.67 & 0.75 & 81.33 & 0.05 \\
\hline 2. Chronic pain & 30.00 & 40.00 & 0.003 & 40.00 & 1.0 \\
\hline 3. Fluctuation-related pain & 12.00 & 56.33 & $<0.0001$ & 44.00 & $<0.0001$ \\
\hline 4. Nocturnal pain & 28.67 & 57.33 & $<0.0001$ & 66.00 & 0.41 \\
\hline 5. Oro-facial pain & 14.00 & 13.00 & 0.71 & 13.33 & 0.76 \\
\hline 6. Discoloration, oedema/swelling & 23.33 & 31.67 & 0.009 & 30.33 & 0.54 \\
\hline 7. Shooting pain/pins \& needles & 22.00 & 42.33 & $<0.0001$ & 41.67 & 0.65 \\
\hline
\end{tabular}

† Proportion of subjects with positive response.

KPP Questionnaire/Scale: King's Parkinson's Disease Pain Questionnaire/Scale.

* Chi-square for prevalence, patients vs. controls.

${ }^{* *}$ McNemar test for prevalence with KPPQ vs. KPPS in patients.

Bonferroni correction: $p=0.0024$. 
Table 2 - Correlations of the the King's Parkinson's Disease Pain Questionnaire total score

\begin{tabular}{|l|l|c|}
\hline & Measure & Spearman r \\
\hline With other pain measures & KPPS total score & 0.80 \\
& VAS Pain (frequency * severity) & 0.31 \\
& PDQ-8 Item 8 & 0.46 \\
& EQ-5D Item Pain/Discomfort & 0.32 \\
\hline With PD-related variables & SCOPA - Motor & 0.42 \\
& Non-Motor Symptoms Scale & 0.47 \\
& Clinical Impression of Severity Index-PD & 0.37 \\
& Parkinson's Disease Sleep Scale & 0.57 \\
& Parkinson's Disease Questionnaire-8 items & 0.56 \\
& Hoehn and Yahr staging & $0.15^{*}$ \\
& Levodopa-equivalent daily dose & 0.24 \\
\hline With other measures & HADS - Anxiety & 0.45 \\
& HADS - Depression & 0.43 \\
& EQ-5D & -0.45 \\
\hline
\end{tabular}

All coefficient values, $p \leq 0.001$, except ${ }^{*}, p=0.008$. 
Table 3 - Test-retest reliability of the King's Parkinson's Disease Pain Questionnaire

\begin{tabular}{|c|c|c|c|}
\hline \multirow{2}{*}{ Items } & \multirow{2}{*}{$\begin{array}{c}\text { Agreement } \\
(\%)\end{array}$} & \multicolumn{2}{|c|}{ Kappa } \\
\hline & & kappa & $\mathrm{Cl} 95 \%$ \\
\hline 1. Pain around joints & 96.2 & 0.85 & $0.65-1.00$ \\
\hline 2. Pain related to internal organ & 92.3 & 0.73 & $0.49-0.98$ \\
\hline 3. Generalised non-specific pain in your stomach area & 96.2 & 0.85 & $0.65-1.00$ \\
\hline 4. Pain deep within the body & 88.5 & 0.68 & $0.44-0.91$ \\
\hline 5. Dyskinetic pain & 82.7 & 0.44 & $0.15-0.73$ \\
\hline 6. Painful cramps in a region during "off" periods & 84.6 & 0.69 & $0.49-0.89$ \\
\hline 7. Generalized "off" period pain & 92.3 & 0.82 & $0.65-0.99$ \\
\hline 8. PLM or RLS-associated pain & 96.2 & 0.91 & $0.78-1.00$ \\
\hline 9. Pain while turning in bed & 94.2 & 0.88 & $0.75-1.00$ \\
\hline 10. Pain when chewing & 96.2 & 0.65 & $0.20-1.00$ \\
\hline 11. Pain due to grinding teeth & 100 & 1.00 & $1.00-1.00$ \\
\hline 12. Burning sensation in the mouth & 100 & 1.00 & $1.00-1.00$ \\
\hline 13. Burning pain in the limbs & 94.2 & 0.82 & $0.63-1.00$ \\
\hline 14. Shooting pain/pins \& needles & 92.3 & 0.84 & $0.69-0.99$ \\
\hline
\end{tabular}


Table 4 - Screening potential of pain modalities using the King's Parkinson's Disease Pain Questionnaire when considering the King's Parkinson's Disease Pain Scale as the gold standard

\begin{tabular}{|c|c|c|c|c|c|}
\hline Items & Sensitivity & Specificity & $\begin{array}{c}\text { Positive } \\
\text { Predictive Value }\end{array}$ & $\begin{array}{l}\text { Negative } \\
\text { Predictive Value }\end{array}$ & Accuracy \\
\hline 1. Pain around joints & $95.1 \%$ & $92.9 \%$ & $98.3 \%$ & $81.3 \%$ & $94.7 \%$ \\
\hline 2. Pain related to internal organ & $77.8 \%$ & $95.8 \%$ & $83.1 \%$ & $94.2 \%$ & $92.0 \%$ \\
\hline $\begin{array}{l}\text { 3. Generalised non-specific pain } \\
\text { in your stomach area }\end{array}$ & $79.2 \%$ & $93.9 \%$ & $73.7 \%$ & $95.5 \%$ & $91.3 \%$ \\
\hline 4. Pain deep within the body & $75.8 \%$ & $87.8 \%$ & $74.2 \%$ & $88.7 \%$ & $84.0 \%$ \\
\hline 5. Dyskinetic pain & $66.7 \%$ & $93.6 \%$ & $68.0 \%$ & $93.2 \%$ & $89.0 \%$ \\
\hline $\begin{array}{l}\text { 6. Painful cramps in a region } \\
\text { during "off" periods }\end{array}$ & $90.8 \%$ & $72.3 \%$ & $61.4 \%$ & $94.2 \%$ & $78.3 \%$ \\
\hline 7. Generalized "off" period pain & $70.1 \%$ & $88.4 \%$ & $63.5 \%$ & $91.2 \%$ & $84.3 \%$ \\
\hline 8. PLM or RLS-associated pain & $85.7 \%$ & $88.0 \%$ & $73.5 \%$ & $94.1 \%$ & $87.3 \%$ \\
\hline 9. Pain while turning in bed & $91.6 \%$ & $91.1 \%$ & $90.3 \%$ & $92.3 \%$ & $91.3 \%$ \\
\hline 10. Pain when chewing & $80.0 \%$ & $98.6 \%$ & $80.0 \%$ & $98.6 \%$ & $97.3 \%$ \\
\hline 11. Pain due to grinding teeth & $76.5 \%$ & $98.2 \%$ & $72.2 \%$ & $98.6 \%$ & $97.0 \%$ \\
\hline $\begin{array}{l}\text { 12. Burning sensation in the } \\
\text { mouth }\end{array}$ & $75.0 \%$ & $99.0 \%$ & $66.7 \%$ & $99.3 \%$ & $98.3 \%$ \\
\hline 13. Burning pain in the limbs & $65.5 \%$ & $92.7 \%$ & $66.7 \%$ & $92.3 \%$ & $87.7 \%$ \\
\hline $\begin{array}{l}\text { 14. Shooting pain/pins \& } \\
\text { needles }\end{array}$ & $92.8 \%$ & $93.7 \%$ & $91.3 \%$ & $94.8 \%$ & $93.3 \%$ \\
\hline Domains & Sensitivity & Specificity & $\begin{array}{c}\text { Positive } \\
\text { Predictive Value }\end{array}$ & $\begin{array}{c}\text { Negative } \\
\text { Predictive Value }\end{array}$ & Accuracy \\
\hline 1. Musculoskeletal pain & $95.1 \%$ & $92.9 \%$ & $98.3 \%$ & $81.3 \%$ & $94.7 \%$ \\
\hline 2. Chronic pain & $80.0 \%$ & $86.7 \%$ & $80.0 \%$ & $86.7 \%$ & $84.0 \%$ \\
\hline 3. Fluctuation-related pain & $92.4 \%$ & $72.0 \%$ & $72.2 \%$ & $92.4 \%$ & $81.0 \%$ \\
\hline 4. Nocturnal pain & $94.0 \%$ & $89.4 \%$ & $91.9 \%$ & $92.2 \%$ & $92.0 \%$ \\
\hline 5. Oro-facial pain & $85.0 \%$ & $98.1 \%$ & $87.2 \%$ & $97.7 \%$ & $96.3 \%$ \\
\hline $\begin{array}{l}\text { 6. Discoloration, } \\
\text { oedema/swelling }\end{array}$ & $79.1 \%$ & $89.0 \%$ & $75.8 \%$ & $90.7 \%$ & $86.0 \%$ \\
\hline 7. Shooting pain/pins \& needles & $92.8 \%$ & $93.7 \%$ & $91.3 \%$ & $94.8 \%$ & $93.3 \%$ \\
\hline
\end{tabular}




\section{PD PAIN QUESTIONNAIRE}

Name:

Date:

Date of birth:

Centre:

Male

Female

\section{PAIN IN PARKINSON'S}

The movement symptoms of Parkinson's are well known. However, other problems like pain can occur as part of the condition or its treatment. It is important that the doctor knows about the specific type of your pain, particularly if it is troublesome for you.

Several types of pain are listed below. Please:

- Tick the box "Yes" if you have experienced this particular type of pain during the past month.

- If you have not experienced the type of pain in the past month tick the "No" box.

- The doctor or nurse may ask you some additional questions to help you decide.

Please note that this questionnaire only relates to the pain you experienced in the last 30 days.

\section{HAVE YOU EXPERIENCED ANY OF THE FOLLOWING IN THE LAST MONTH?}

1. Pain around the joints (including pain related to arthritis)

2. Pain related to a specific internal organ

(for example, pain around the liver, stomach or bowels)

3. Generalised non-specific pain in your stomach area.

4. Non-specific pain deep within the body: a generalised constant, dull, aching pain

5. Pain related to abnormal involuntary movements (dyskinetic pain)

6. Painful muscle cramps in a specific region during "off" periods

(when your medication is not working).

7. Generalised pain during "off" periods

(pain in the whole body or areas that are not affected by muscle cramps)

8. Pain related to jerking leg movements during the night or an unpleasant burning sensation in the legs which improves with movement (restless legs syndrome)

9. Pain related to difficulties when turning in bed at night

10. Pain when chewing

11. Pain related to grinding teeth during the night

12. Burning sensation in your mouth.

13. Burning pain in the limbs (often associated with swelling or medication).

14. Shooting pain/pins and needles down the limbs 


\section{Supplementary material}

\section{Assesments}

For both patients and controls, information regarding age, sex, and ethnicity was collected. For patients, information regarding the duration of PD (in years), years of treatment for PD, current treatment, and surgery was also addressed.

In addition to the KPPQ, information for each patient was collected using the following validated instruments for PD:

1. The KPPS [13], a specific measure of different pain modalities for PD patients. It includes 14 items grouped in seven domains (musculoskeletal, chronic, fluctuation-related, nocturnal, orofacial, discolouration and oedema/swelling, and radicular pain). The score for each item is the product of severity ( 0 to 3 ) and frequency ( 0 to 4 ). Total scores for each domain are obtained by summing the corresponding items and for the overall scale by summing the domain scores.

2. The original Hoehn and Yahr classification (HY), which measures the staging of PD on a scale from one to five with one being unilateral expression of disease and five being the most severe stage [16].

3. The Scales for Outcomes in Parkinson's Disease-Motor (SCOPA-Motor), which measures motor impairment (10 items), activities of daily living (7 items), and motor complications (4 items) [17].

4. The Non-Motor Symptoms Scale for PD (NMSS) [18], a 30-item questionnaire grouped in 9 domains: cardiovascular (2 items), sleep/fatigue (4 items), mood/cognition (6 items), perceptual problems/hallucinations ( 3 items), attention/memory ( 3 items), gastrointestinal tract ( 3 items), urinary function ( 3 items), sexual function ( 2 items), and miscellaneous (4 items).

5. The Clinical Impression of Severity Index for PD (CISI-PD) [19], a clinical estimate of the PD global severity in four areas: motor signs, disability, motor complications, and cognitive status.

6. Visual Analog Scales (VAS) for pain severity and frequency [20]. A total score (VAS-TS) was obtained by multiplying the two individual scores.

7. Hospital Anxiety and Depression Scale (HADS) [21], a self-administered, 14-item instrument to measure depression and anxiety disorders in non-psychiatric outpatients.

8. European Quality of Life - 5 Dimensions Scale (EQ-5D) [22], a generic, preference-based health-related quality of life (HRQoL) measure. It includes three components: (1) a descriptive part, consisting of 5 items, that can then be converted into a value (EQ-Index) representing the overall HRQoL; (2) a question about change in health status in the preceding 12 months; and (3) a visual analogue scale (EQ-VAS) for assessment of current health state.

9. PD Quality of Life Questionnaire (PDQ-8) [23], an 8-item instrument that specifically measures HRQoL in PD; 
10. Parkinson's Disease Sleep Scale-Version 2 (PDSS-2) [24], an updated version of the 15item PDSS.

\section{Data Analysis}

Data from each center were anonymized and sent to the National Center of Epidemiology, Carlos III Institute of Health, Madrid (Spain) for analysis under the supervision of PMM.

Distribution of data was not normal (Shapiro-Francia test); therefore, non-parametric statistics were used. For each participant, a KPPQ "total score" (KPPQ-TS) was calculated by summing the number of "Yes" responses. Also, to compare the performance of the KPPQ with the KPPS that was taken as "gold standard," the KPPQ items were grouped in domains according to those of the scale.

Differences between patients and controls with respect to demographic data were analyzed using the chi-square and Mann-Whitney $U$ tests. The prevalence of the diverse types of pain assessed in the questionnaire was determined for each item by the proportion of individuals responding positively. In patients, a comparison of the prevalence for each item obtained from the KPPS application was carried out considering a score of 0 as the absence of the symptom and a score $\geq 1$ ("positive response") as indicative of the presence of the symptom. The McNemar chi-square test was used to determine the statistical significance of the differences.

Furthermore, Spearman rank correlation coefficients between the KPPQ-TS and scores of the other aforementioned pain measures were assessed to determine convergent validity. In addition, the correlation between the KPPQ-TS and other variables in the study was calculated. A high correlation ( $r S>0.70$ ) was hypothesized with the KPPS total score (sum of the 14 items' scores), whereas moderate or weak correlations ( $r S=\leq 0.70)$ [26] were expected with other PD and generic measures.

For test-retest reliability, the percentage of agreement, Cohen's kappa index for items, and ICC (1-way, random effect) for the KPPQ-TS were determined.

Cohen's kappa was used to determine the concordance between the prevalence detected by corresponding items of KPPQ and KPPS. In addition, a KPPS "total score of prevalence" was calculated as with the KPPQ-TS, and intraclass correlation coefficient (ICC, 2-way, random effect) was used to further analyze the concordance between both "total scores." 
Finally, sensitivity, specificity, positive and negative predictive values, and accuracy of the KPPQ items and domains were calculated against the corresponding components of the KPPS, which were considered the gold standard. 